\title{
To the question of the building information modeling technologies transition to a new development level
}

\author{
Leonid Shilov and Liubov Shilova* \\ Moscow State University of Civil Engineering, 129337, Moscow, Russia
}

\begin{abstract}
The article analyzes the maturity level of information modeling technology based on the Bew-Richards diagram, as well as using the Gartner curve. The analysis of current publications on the keywords BIM and Building information modeling has been carried out. It has been determined that Revit software is currently the most widely used for working with construction objects, but the proposed Bentley products provide more granularity in the information model characteristics. At the same time, none of the presented products can cover the entire life cycle of a construction project without significant modifications. The authors propose to expand the set of building structures elementsэ properties, dividing them into more detailed subgroups, to use this information at further stages of the release of design documentation. Thus, the information in the model should be sufficient to release all subsequent documentation. In this case, in addition of the need to separate them in detail, information about the position of the object in world space, and not in model space, is added to the properties. As a result, it is possible to build an information system containing information sufficient for the release of all project documentation according to the proposed approach, as well as supporting the project at the operational stage. In this case, the documentation issuance is proposed to be done by writing scripts and using databases.
\end{abstract}

\section{Introduction}

There is an active integration of information technologies into activities related to the construction of buildings and structures for various purposes nowadays. At the same time, information modeling technology is the most popular. This fact is confirmed by a significant number of publications - 7392, presented in the international Scopus database, for the keywords "BIM" and "building information modeling". Fig.1 shows the distribution of publications by areas of science.

As it can be seen from Fig. 1, the largest number of publications relates to engineering sciences and informatics, with most of the publications attributed to both groups, which confirms the close integration of information technologies in the classical sense with the use

\footnotetext{
* Corresponding author: ShilovaLA@mgsu.ru
} 
of programming in technical sciences. In this regard, further analysis of articles was carried out only for the publications included in these two groups.

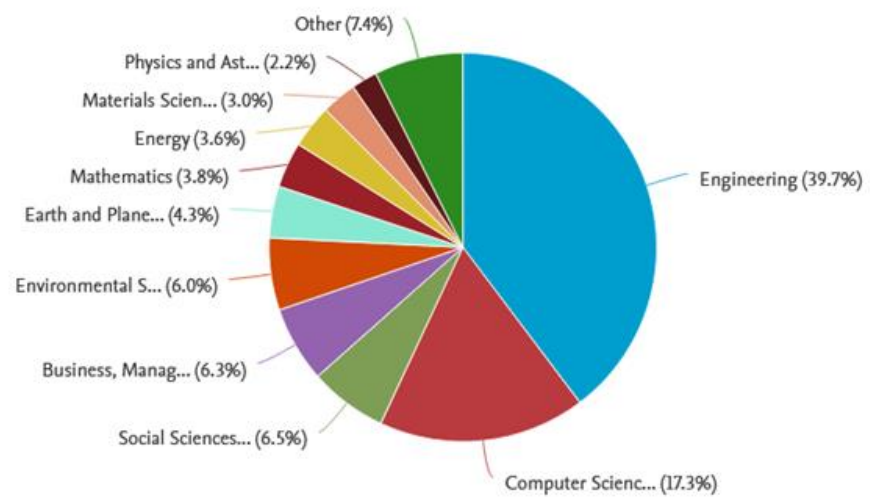

Fig. 1. Papers by subject area

In total 6339 articles are published for the period from 1992 to 2021 . The distribution of publications by year is shown in Fig. 2a.

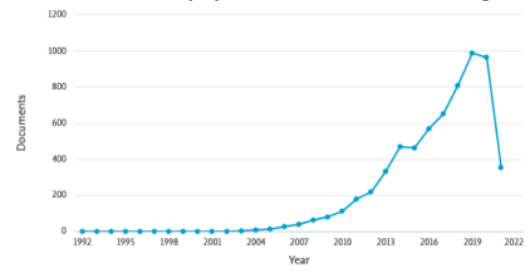

a. documents by year

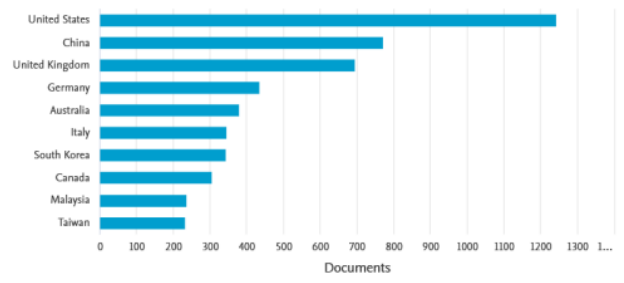

b. Document by country or territory (the document counts for up to 15 countries/territories are compared)

Fig. 2. Statistics on publications from the sample in question

As it can be seen from Fig. 2a, the largest increase in publications has been noted since 2010.The distribution of publications by countries of the world is shown in Fig. $2 \mathrm{~b}$, the leaders are authors from the USA (1241 publications), in the second place is China with 769 publications, in the third place is Great Britain with 693 publication.

All this confirms that information modeling technologies, the active development of which began in 2010, are still at the stage of their formation and interest in their development is growing.

Considering the development of information modeling technology, several stages can be distinguished. The beginning of the development of information modeling technologies is considered to be two-dimensional drawing using CAD. The next level of information modeling technologies development is considered to be full-fledged three-dimensional modeling in the environment of common data using CAD. The frontier for the development of information modeling technologies is a single integrated system that provides support for the entire life cycle.

The considered gradation of the information modeling technologies' development levels was developed in 2008 by Mark Bew and Mervyn Richards to describe the levels of information modeling in BIM in the UK (Fig. 3) and previously reviewed in more detail by the authors [1-2]. 


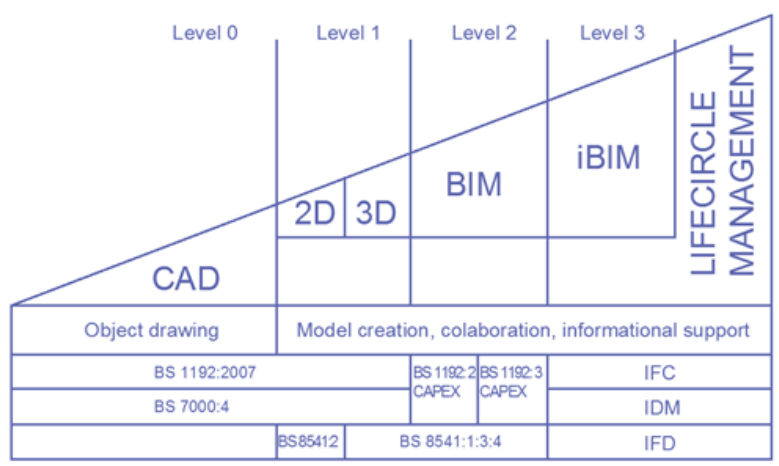

Fig.3. Maturity level diagram of information modeling technologies

Thus, according to the maturity level diagram, not only 2D and 3D measurements are distinguished, but also 4D, adding "time" to the information model, that is, the building construction process can be viewed as it progresses, and 5D - Cost - the ability of BIM models to contain information on costs and quantities / specifications, including real-time cost estimates. The development ideal is the so-called 6D BIM. 6D implies the organization of connections between three-dimensional components of the object with all aspects of control over the entire time interval of the object. Thus, 6D BIM is the pinnacle of the evolution of Bew-Richards diagram information modeling technologies.

At the same time, it is possible to determine the maturity of information modeling technologies using the Gartner curve [3] (Fig. 4).

The Hype cycle, also called the maturity cycle, describes the gradual development of a technological innovation as it matures. Moreover, each innovation goes through 5 stages, each of which is characterized by a different degree of interest on the part of society and specialists:

- Technology trigger - the first mention (publication) about a new technology;

- Peak of Inflated Expectation - the peak of the popularity of the new technology, due to the huge expectations from the new technology;

- Trough of Disillusionment - technology's drawbacks are revealed;

- Slope of Enlightenment - refinement of the technology in order to eliminate the main shortcomings, and start its implementation in commercial projects;

- Plateau of Productivity - the onset of technology maturity, the community takes the technology for granted, realizing its advantages and limitations.

Currently, according to the authors, information modeling technologies are at the stage of overcoming the shortcomings (Slope of Enlightenment), since the existing international experience makes it possible to identify the main problems in the development and active implementation of the technology.

For the active implementation of these technologies, documents that regulate the norms and rules of the information modeling technology implementation, both in Russia and abroad, are developed. However, these materials of these documents are scattered and sometimes conducted in diametrically opposite directions. This indicates that the area under consideration is in search of an optimal solution that meets the requirements of construction tasks, which would allow linking all stakeholders working on the project: designers, experts conducting an examination, project managers, etc. 


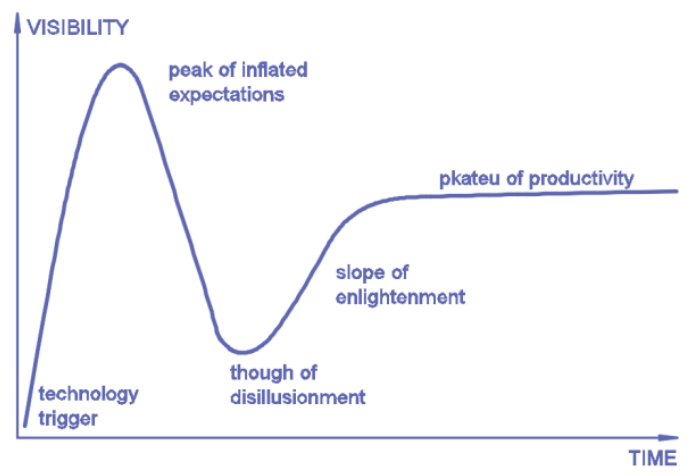

Fig. 4. Gartner curve for determining technology maturity

In the UK and most European countries, only those projects that are carried out using information modeling technologies receive government support. In Russia, the transition to work with projects in BIM was announced in 2022. However, it is still too early to talk about a plateau in technology productivity.

The article presents a conceptual approach that allows for further synergy of information modeling technologies and information technologies in the classical sense and move BIM to a new development level.

\section{Methods}

VosViewer software was used to analyse bibliometric information about publications. Fig. 5 shows the relationship between the keywords of publications from the above sample in the area under consideration. The minimum number of keyword hits in the selected publications was set to 40 . The threshold value was 182 out of 26140 words. For each of 182 keywords, the program calculated the frequency of simultaneous links with other keywords. After checking the suggested keywords, the 50 most relevant options were selected within the research topic.

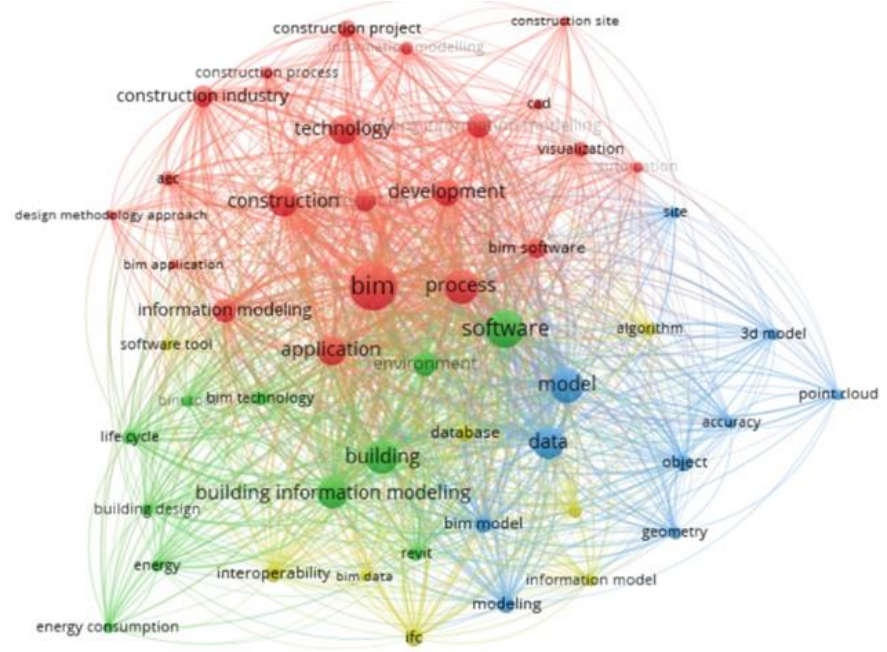

Fig. 5. Cluster map generated by research results of the keywords «bim» and «building information modeling» 
According to Fig.5 four clusters can be distinguished, from which currently BIM technologies are mainly used in the construction industry (cluster 1 highlighted in red includes such keywords as Cad system, construction site, visualization, etc.), the main focus is on the visualization of the construction object, however, during the creation of the working documentation for the project, this information is not enough.

On the other hand, cluster 2 (in green) describes the prospects for using information modeling technologies to improve the energy efficiency of buildings. Cluster 3 (highlighted in blue) describes the approach to using point clouds to create information models. Cluster 4 - describes the formats for presenting models for further use.

In the reviewed works [4-21] research in the development of information modeling technologies and the implementation of construction projects is mainly carried out using Revit software. A little research works is dedicated to the technological capabilities of Bentley [22-26].

Thus, it should be noted that despite a significant number of publications and research in this area, the development of information modeling technologies is rather slow. However, none of the solutions allows us to say that the software product covers all the needs of the designer, at least in the 4D dimension.

At the moment, in order to organize support for construction at different stages of the life cycle, specialists follow the path of building a system based on a set of products, linking the design model with estimates and/or organizing the master plan, but these solutions require significant manual effort. An example of such problems is the task of exporting models for loading them into a computational complex, in this case it is easier to create a computational model from scratch or the problem of compatibility of IFC files, where a change in the design model leads to manual correction of parts of projects based on this information.

As a result of the research, the software products of Autodesk and Bentley were selected and analysed as the most demanded and promising products on the market.

\section{Results and discussions}

Let's consider the software products of Autodesk and Bentley companies taking into account the BIM maturity level diagram. At the first level according to the Bew-Richards diagram, 3D modeling of an object is possible, while the properties of the object are usually limited by area and /or volume. For example, in Fig. 6a presents the characteristics of a 3D element, built in Autocad, which contain information only about the location of the object and its dimensions. As it can be seen from the figure, there is no possibility of setting object properties.

At the next development level of information modeling technologies, the constructed building objects in Revit software (for example) contain information about the elements of building structures, including: the shape and volume of the element, the total area of its surfaces and material properties. Fig. $6 \mathrm{~b}$ shows the properties of the floor, created in the Autodesk Revit software product, where from the characteristics of the information model it can be taken the specifications of volumes and materials, which are transferred to the annotation and creation of the construction organization project. 


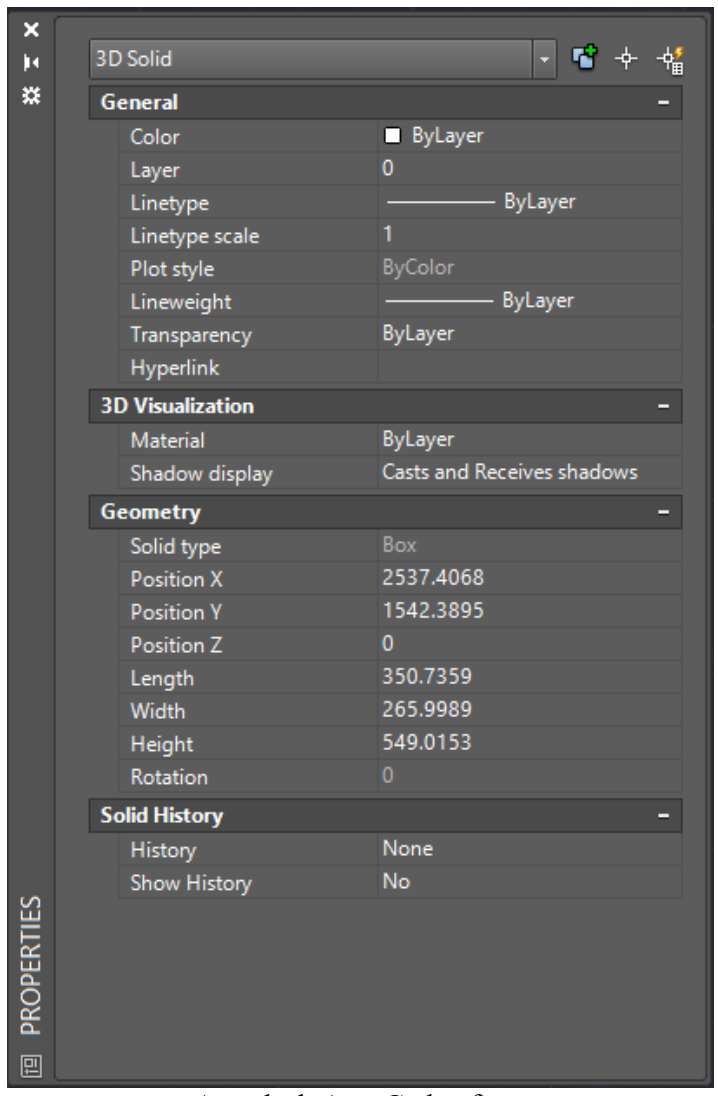

a Autodesk AutoCad software

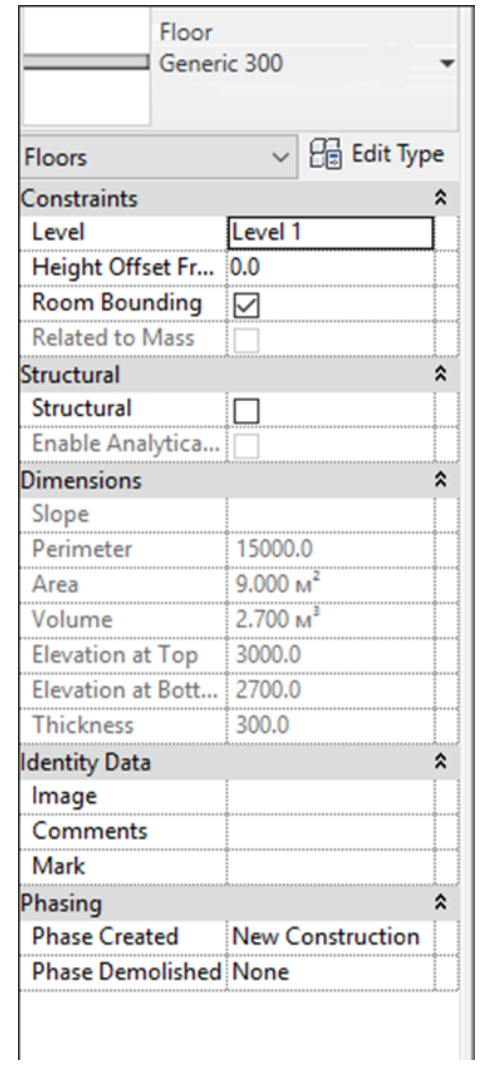

b Autodesk Revit software

Fig. 6. Properties of an object designed in different software

However, the selection of mechanisms and scope of work included in the manufacture of the element is carried out manually. The authors propose to expand the set of properties of building elements, dividing them into more detailed subgroups, to use this information at further stages of the release of design documentation. Thus, the information about the model should be sufficient for the release of all subsequent documentation. In this case, to the properties it is necessary to add information about the position of the object in world space, and not in model space (as has been done now, when something abstract is taken at the zero mark), as well as dividing the properties of all elements into more detailed ones (to simplify the process of estimate calculation). Fig. 7 shows a possible variant of this proposed approach.

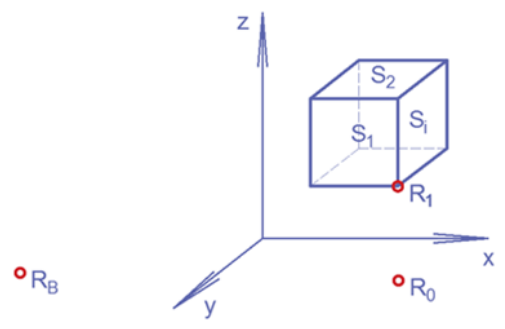

Fig. 7. An illustration of the building element's proposed characteristics 
Possible characteristics of a building structure element are collected in Table 1, where the $\mathrm{R}_{1}$ point (Reference point 1) binds the object to the real location.

Table 1. Proposed characteristics of a building structure element

\begin{tabular}{|l|}
\hline Properties: \\
\hline Volume $_{1}$ \\
\hline Area $_{1}$ \\
\hline Area $_{2}$ \\
\hline$\ldots \ldots$ \\
\hline Area $_{i}$ \\
\hline Concrete strength \\
\hline Reference point $_{1}$ \\
\hline
\end{tabular}

Among the leaders in the BIM software market, Bentley offers the OpenBuildings Designer software product, in which the geometric characteristics of the elements are expanded in more detail (Fig. 8) than in Revit software, however, in accordance with the above goals, even more detailed separation is required, as well as binding to real coordinates of the object.

\begin{tabular}{|ll|}
\hline \multicolumn{1}{l|}{ Quantities } \\
\hline Area (Gross) | Side & $2.6741 \mathrm{~m}^{2}$ \\
Area (Net) | Side & $2.6741 \mathrm{~m}^{2}$ \\
Area (Gross) | Top & $17.5835 \mathrm{~m}^{2}$ \\
Area (Net) | Top & $17.5835 \mathrm{~m}^{2}$ \\
Area (Gross) | Bottom & $17.5835 \mathrm{~m}^{2}$ \\
Area (Net) |Bottom & $17.5835 \mathrm{~m}^{2}$ \\
Perimeter & $17827.5 \mathrm{~mm}$ \\
Elevation | Top of Slab & $0.0 \mathrm{~mm}$ \\
Elevation | Bottom Of Slat & $-150.0 \mathrm{~mm}$ \\
Volume (Gross) & $2.6375 \mathrm{~m}^{3}$ \\
Volume (Net) & $2.6375 \mathrm{~m}^{3}$ \\
\hline
\end{tabular}

Fig. 8. Properties of an object designed in Bentley software

In the presented example dividing the surface area into areas that are located above, below and on the sides of the volume will allow the estimate department to immediately receive information not only about the required area of the construction formwork, but also, depending on the location of the object's planes in space (point $\mathrm{R}_{1}$ ), select the necessary mechanisms for the construction of this structure. Thus, if the object is located at elevation $\mathrm{R}_{1}$ from the ground elevation $\left(\mathrm{R}_{0}\right)$, then it is possible to make a calculation for the selection of the necessary construction machines and mechanisms, for example, for the construction of an object, the crane height can be calculated by the formula:

$$
H=R_{1}-R_{0}+h_{e}+h_{m}
$$

Where $\mathrm{H}$ is the required crane height;

$\mathrm{R}_{1}$ is an element location mark;

$\mathrm{R}_{0}$ defines ground level;

$\mathrm{h}_{\mathrm{e}}$ is a building element height;

$\mathrm{h}_{\mathrm{m}}$ is a necessary headroom for crane manipulation.

In the proposed approach, such a calculation will not be difficult to make. Also, knowing the construction point $\mathrm{R}_{0}$ and the location of the material supplier or the location of the concrete batching plant $\left(R_{B}\right)$, it is possible to calculate the delivery distance and thereby 
obtain the logistics costs. These and other formulas are proposed to be further driven into scripts.

Breakdown of planes and understanding of their direction: vertical or horizontal plane, allows us to conclude that formwork is necessary, for example, that vertical formwork is definitely needed (except for the case of adjoining another concrete block), formwork from above is not needed, formwork from below is needed, but depending on the position element and its abutment to other elements, it can be a scaffolding structure for overlapping, or laying concrete as a base on concrete preparation. Thus, it is important to fix the position of an element in space and its abutment to other elements.

Subsequently, it is proposed to develop scripts in order to automate the release of estimates, the COP section (construction organization project), the schedule, etc., thus, the release of project documentation will consist of an information model of elements containing these (or slightly supplemented properties), and all the rest will be a set of code that links these elements with estimates and other regulatory frameworks, which eliminates the need for manual selection of machines and mechanisms when planning estimates and labor production.

Fig.10 shows an illustration of the proposed characteristics of a building element for two temporary states.

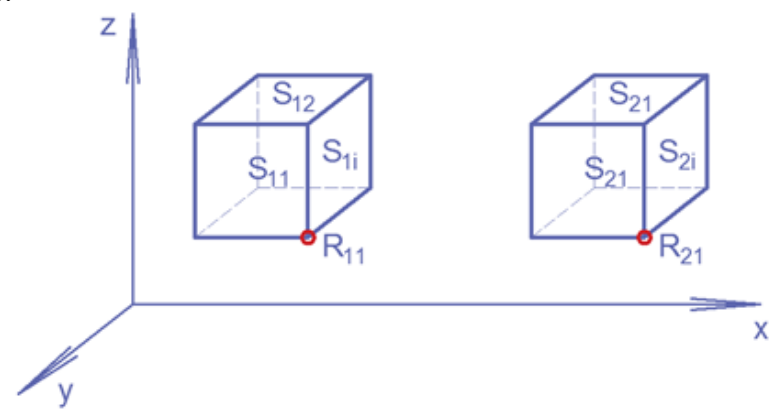

\begin{tabular}{|c|}
\hline Properties of stage 1: \\
\hline Volume1 \\
\hline Area11 \\
\hline Area12 \\
\hline$\ldots \ldots$ \\
\hline Areali \\
\hline Concrete strength1 \\
\hline Reference point11 \\
\hline
\end{tabular}

\begin{tabular}{|c|}
\hline Properties of stage 2: \\
\hline Volume2 \\
\hline Area21 \\
\hline Area22 \\
\hline$\ldots \ldots$ \\
\hline Area2i \\
\hline Concrete strength2 \\
\hline Reference point 21 \\
\hline
\end{tabular}

Fig. 10. Property of a building structure element in two states

Since it is possible to make a database containing not only the design state of an element, but also to include various states of an object with changed properties (such as volume, area, position in space), it becomes possible to analyze the state of a construction object and we can talk about the possible completion of the Bew-Richards diagram.

\section{Conclusion}

As a result, a user (for example designer) can have CAD solutions for visualizing building structures and all other stages of design documentation can be performed based on the properties data of structural elements using programming languages. 
This approach will allow unloading data from the model, processing them to create an end-to-end information system at all stages of the existence of a construction object, which confirms the possibility of further merging of information technologies and additional processing of BIM technologies based on them.

A fixed position of a building object in space can simplify and then automate the development of sections for organizing construction and an estimate section.

\section{References}

1. A. Ginzburg, L. Shilova, A. Adamtsevich, L.Shilov, J. of App.Eng.Sci. 14(4) 457-460 (2016)

2. A. Ginzburg, L. Shilova, L. Shilov, Matec WoC 251, 05001 (2018)

3. P. Bosch-Sijtsema, C. Claeson-Jonsson, M. Johansson, M. Roupe Con.Inn. (2021) in print

4. J.P. Carvalho, L. Bragança, R. Mateus, Com.in In. 127, 103400 (2021)

5. G. Desogus, E. Quaquero, G. Rubiu, G. Gatto, C. Perra Sus 13(8), 4496 (2021)

6. J. Ma, S. Ding, D. Zhang, Y. Li, IOP Con. Ser. EES 1802 (4), 042026 (2021)

7. P. Zhao, X. He Arab. J. of Geosc. 14(4), 305 (2021)

8. M. Nik-Bakht, J. Lee, S.H. Dehkordi, J. of Inf. Tech. in C. 26, 28-38 (2021)

9. X. Xiong, Adv. In Int. Sys. And Com. 1342 AISC, 164-171 (2021)

10. M.B. Seo, D. Lee, App. Sci. 10(22) 8118, 1-13 (2020)

11. A.M. Abd, A.H. Hameed, B.M. Nsaif Asi, J. of Civ. Eng. 21(7), 1249-1257 (2020)

12. F. Rodrigues, F. Antunes, R. Matos Cons. Inn. 21(2), 244-258 (2020)

13. Y. Jin, J. Seo, J.G. Lee, S. Ahn, S. Han, App. Sci. 10(17), 5915 (2020)

14. T. Wei, Y. Chen, J. of Am. Int. and H. Com. 11(9), 3699-3706 (2020)

15. N.Q. Toan, N.T.T. Hang, L.H. Nam, D.H. Duyen, T.P. Nam, IOP Conf. Ser.: MSE 869(6), 062007 (2020)

16. A. Kamunda, S. Renukappa, S. Suresh, H. Jallow, Eng., Cons. And Arc. M. 28(2), 510529 (2020)

17. J.P. Carvalho, L. Bragança, R. Mateus, App. Sci. 10(13), 4444 (2020)

18. I. Alecrim, J.P. Carvalho, L. Braganca, R. Mateus, IOP Conf. Ser.: EES 503(1), 012005 (2020)

19. F.N. Aryanti, R.R.T. Busono, S. Siswoyo, IOP Conf. Ser.: MSE 530(4), 042054 (2020)

20. R.R.J. Al Doury, T.K. Ibrahim, T.K. Salem, J. of Mec. Eng. Res. And Dev. 43(6), 497513 (2020)

21. M. Shick Alshabab, A. Vysotskiy, M. Petrichenko, T. Khalil, Lec. N. in Civ. Eng. 70, 413-421 (2020)

22. S. Fabozzi, S.A. Biancardo, R. Veropalumbo, E. Bilotta, Tun. and Und. Sp. Tech. 108, 103723 (2021)

23. C. Liu, J. of Rail. Eng. Soc. 36(6), 91-96 (2019)

24. M. Khaddaj, I. Srour Prc. Eng. 145, 1526-1533 (2016)

25. X. Sheng, H. Luo, P. Wang, App.Mec. and Mat. 587-589, 1091-1094 (2014)

26. E. Joyce, T. Sawyer, ENR 273 (20), (2014) 